\title{
Curanderismo, etnicidad y justicia. Sobre una causa criminal en la frontera sur de Córdoba del Tucumán en las postrimerías del siglo XVIII
}

\author{
Curanderismo, Ethnicity and Justice. On a Criminal Record \\ in the Southern Border in Córdoba del Tucuman \\ at the End of $18^{\text {th }}$ Century
}

\author{
María Dolores Rivero \\ ORCID iD: https://orcid.org/0000-0002-0068-3281 \\ Centro de Investigaciones y Estudios sobre Cultura y Sociedad, \\ Universidad Nacional de Córdoba/CONICET, Argentina \\ Cecilia Moreyra \\ ORCID iD: https://orcid.org/0000-0003-4612-7851 \\ Universidad Nacional de Córdoba/CONICET, Argentina
}

\begin{abstract}
El presente artículo tiene por objeto analizar los posicionamientos y estrategias desplegadas en un mercado terapéutico específico. El examen se sustenta en un expediente criminal en que se acusa a un sujeto de etnia mulata de practicar curanderismo en la frontera sur de Córdoba del Tucumán a finales del siglo XVIII. El abordaje microhistórico propuesto permite urdir una trama compleja en la que interaccionan jerarquías socioétnicas coloniales, prácticas de curar ubicadas en los márgenes de la medicina diplomada y las formas de aplicación de la justicia.
\end{abstract}

Palabras Clave: Curanderismo; Etnicidad; Justicia; Tucumán; Siglo XVIII.

This article aims to analyze the positions and strategies deployed in a specific therapeutic market. The inquiry is based on a criminal record in which a mulato is accused of curanderismo in the southern border in Córdoba del Tucumán at the end of $18^{\text {th }}$ century. The microhistorical approach allows to wave a complex plot in which interacts socioethnical hierarchies in a colonial context, practices of healing situated in the limits of certified medicine and forms of application of justice.

KeYwords: Curanderismo; Ethnicity; Justice; Tucumán; $18^{\text {th }}$ Century.

Copyright: (C) 2021 CSIC. Este es un artículo de acceso abierto distribuido bajo los términos de la licencia de uso y distribución Creative Commons Reconocimiento 4.0 Internacional (CC BY 4.0). 


\section{Introducción}

En el año 1789, en la región sur y fronteriza de Córdoba, un sujeto - Roque de Lamar - es acusado de haberse introducido de médico en aquella zona; la causa criminal lleva como título «por curandero». La génesis del delito por el cual debe comparecer ante la justicia es, concretamente, la enfermedad y muerte del comandante don Juan Gualberto Soria, quien, según lo comentado por los declarantes, fuese asistido por De Lamar a partir de la utilización de elementos naturales. El expediente en cuestión cuenta con ciertos elementos clásicos susceptibles de ser hallados en la pletórica serie de Crimen del Archivo Histórico de la Provincia de Córdoba: un juez pedáneo, testigos, un fiscal, un abogado defensor y un supuesto reo. Este último, en nuestro estudio, se constituye en una suerte de «anfibio cultural», pues nada no sólo «entre la(s) cultura(s) popular(es) y la cultura de elite o entre grupos sociales, sino también entre variadas culturas y grupos étnicos». ${ }^{1}$ A partir de allí, resulta innegable que estaría expuesto a múltiples miradas y, por su papel en la sociedad (en tanto mulato y sanador), se halló también expuesto a suscitar hostilidades y a estar en el centro de las pugnas de una sociedad marcadamente estratificada.

Los últimos diez años han dado paso al engrosamiento de una vertiente historiográfica —ubicada en el plano de los estudios de la salud y la enfermedad - que se interroga por las faenas de sujetos que pueden ser pensadas en las fronteras o en los márgenes de la biomedicina. Sin embargo, una revisión de esos aportes permite constatar que estamos en presencia de una producción aun exigua en los relativo a estas prácticas para el siglo XVIII. A escala latinoamericana se destacan aproximaciones en torno a fenómenos como la brujería y el curanderismo indígena en el territorio de la Nueva España, que ponderan elementos como la esclavitud, la etnicidad, el cruce cultural y las jerarquías de poder y dominación. ${ }^{2}$ Especialmente, el caso de México muestra cómo las acciones curanderiles, primordiales para la cultura indígena, fueron castigadas y relegadas a pesar de ser elementales para los problemas sanitarios de los grupos marginales. ${ }^{3}$

Estas prácticas no alopáticas también han sido examinadas en algunas regiones de Ecuador, específicamente a partir de personajes situados en

1 Ceballos Gómez, 2001, 52-54.

2 López Pereda, 2014.

3 Quezada, 1989. 
Guayaquil y la península de Santa Elena. ${ }^{4}$ De manera aislada, un estudio de Emanuele Amodio aborda - considerando las especificidades de Venezuela - la búsqueda de la eliminación de posibles alternativas terapéuticas y profesionales a partir de la creación del Protomedicato de Caracas. ${ }^{5}$

La historiografía brasilera viene nutriendo también esta línea analítica. Aunque enfocado en la imbricación entre medicina y fauna silvestre en la región de Minas Gerais, el trabajo de Rafael Freitas e Souza se acerca tangencialmente a la figura del curandero. ${ }^{6}$ Para este mismo estado del sureste de Brasil, Andrés Lima Nogueira avanza sobre las acciones colectivas de «negros curadores», individuos que — siendo esclavos o libertos, africanos o mestizos - fueron identificados como hacedores de «dolencias de hechizos» $\mathrm{y}$, consecuentemente, perseguidos de manera sistemática por las autoridades.?

La agenda de indagación argentina en torno a las medicinas no heterodoxas y que revisita tiempos dieciochescos no escaparía a la tendencia tímida que señaláramos anteriormente para el resto de América Latina. En efecto, el territorio que posteriormente configuraría la Argentina y los curadores que en él circulaban han sido objeto de escasos estudios. Entre ellos, destacan aquellos que colocan en perspectiva analítica hechiceros del Gran Chaco, ${ }^{8}$ y a curanderos y brujas de la gobernación del Tucumán, ${ }^{9}$ espacio que en tiempos coloniales se halló comprendido por las actuales provincias de Jujuy, Salta, Tucumán, Catamarca, La Rioja, Santiago del Estero y Córdoba. En esta línea resultan insoslayables los aportes que pesquisan los juicios y denuncias a partir de una mirada que prioriza las tensiones en torno a las mujeres sanadoras. ${ }^{10}$

Con el fin de abonar en las discusiones de este campo aún fértil, el presente estudio se propone desentrañar los posicionamientos y estrategias de un sujeto que presentaba cierta dualidad; por un lado, se encontraba en la base de la pirámide social colonial y en las afueras de la medicina diplomada. Es decir, sus prácticas no estaban dentro de los límites de la legalidad ni legitimidad otorgadas por el Estado. Por otro, contaba con el aval del cura vicario de la región y con la aceptación de la comunidad de la cual formaba parte. Dicho personaje junto a otros detentores de saberes y ejecutores de

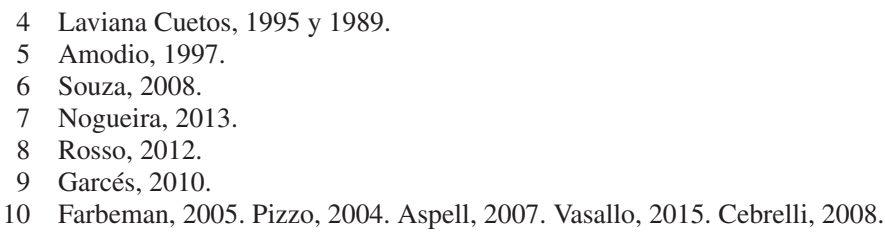


prácticas curativas variadas vertebraron lo que se conoce como mercado terapéutico, concepto que «presenta la ventaja de apertura hacia una concepción de las relaciones entre la medicina universitaria y otras prácticas médicas, no atrapada en la dicotomía más común que separa la medicina académica del resto de ofertas». ${ }^{11}$

Indagar en estas cuestiones supondrá sumergirnos en los laberintos de la historia cultural y del enfoque regional/local, que invita a ir «más allá del territorio», vinculando espacios (construidos socialmente y despegados de una territorialidad específica) con prácticas, experiencias e identidades de actores particulares (pero temporal y espacialmente situados), poniendo simultáneamente de relieve su riqueza como «casos» particulares pero representativos de una historia más amplia. ${ }^{12}$ Optamos, entonces, por una variante que nos conduce a preguntarnos por los sentidos y significados construidos por sujetos que habitaron una época y, para hacerlo, analizamos la dimensión micro de la vida, de la producción, de los imaginarios, de los saberes y las ideas en torno a prácticas vinculadas a la salud. En otros términos, a partir de un estudio microhistórico ${ }^{13}$ — cimentado en los indicios presentes en el expediente judicial de Roque de Lamar-intentaremos otorgarle voz a un integrante de un sector que viene siendo poco «escuchado» por la historiografía tradicional, atendiendo a una cartografía de lo social bajo una clave más densa. ${ }^{14}$ En este sentido, partimos de considerar que las fuentes judiciales son insumos por excelencia, pues permiten observar a través de ellas no solo las figuras oficiales del poder institucional, sino también acceder a territorios poco explorados de los sectores subalternos: allí está registrada su vida cotidiana, su vida material. ${ }^{15}$ De manera concreta, los expedientes no solo habilitan la reconstrucción de un «perfil social de los encausados, sino también explorar la duración de los procesos, las sentencias o las pautas culturales de las clases populares».$^{16} \mathrm{Se}$ trata, en palabras de Arlette Farge, de archivos que se erigen como una «huella en bruto de vidas que de ningún modo pedían expresarse así, y que están obligadas a hacerlo porque un día se vieron enfrentadas a las realidades de la policía y de la represión». ${ }^{17}$

11 Márquez Valderrama, García y Montoya, 2012, 332.

12 Fernández, 2007.

13 Ginzburg, 2016 [1976].

14 Revel, 2015.

15 Mayo, 1999.

16 Rebagliatti, 2018, 113. Grana, 2017.

17 Farge, 1991, 10. 


\section{Los sujetos. Los escenarios}

Todo conocimiento sobre Roque de Lamar será de carácter fragmentado, pues delinear un conjunto de rasgos que lo definan, aunque solo sea en forma aproximada, es factible sólo a partir de las parciales voces que toman parte en el expediente. Sobre el acusado discurrirán los funcionarios de la Justicia, los testigos y el propio Roque, de quien se dirá el nombre, edad, estado civil, oficio y etnia, junto con la información especialmente relevante para el proceso, esto es, las prácticas curativas que venía realizando; el accionar que desencadenó la muerte del comandante Soria y las indefectibles referencias a sus antecedentes delictivos, que incluyen robo de hacienda y violencia física y sexual sobre una mujer. Estas infracciones contribuirán en la construcción de su figura como delincuente, es decir, alguien perjudicial.

Su nombre, ya se sabe, era Roque de Lamar; su edad, dice ignorarla. No obstante, quien le interroga estima que cuenta con más de treinta años. Cálculo que es, por cierto, bastante aproximado, pues el censo de 1778 lo registra con 27 años, y aunque este dato es, acaso, también una estimación, tenemos que, al momento de su procesamiento por curanderismo, Roque rondaba los 38 años. Era natural del Río Cuarto, zona fronteriza ubicada al sur del Virreinato del Río de la Plata, específicamente de la Gobernación Intendencia de Córdoba del Tucumán. Situado a más de 200 km de la ciudad de Córdoba, el partido de Río Cuarto se alzaba en el límite con territorios habitados por población indígena que todavía resistía al avance español. La constitución de fuertes militares en las zonas de frontera se desplegó como parte de la política reformista de los Borbones durante el siglo XVIII, orientada a reforzar estos espacios liminales con miras a prevenir la amenaza de otras potencias, así como los ataques indígenas, perjudiciales para el desarrollo comercial de la región. La militarización de la frontera sur de Córdoba estuvo a cargo del gobernador intendente marqués de Sobremonte, que construyó fuertes y fortines en la zona y promovió la formación de poblaciones en las inmediaciones de estos, estableciendo así, por ejemplo, la villa de Nuestra Señora de la Concepción del Río Cuarto — fundada en 1786 y reconocida como villa real en $1797 \_18$ y el Paraje de San Bernardo con su fuerte del mismo nombre.

18 Rustan, 2005. Olmedo y Tamagnini, 2019. 
Roque estaba casado con María Josefa Suárez, con quien tenía tres hijas, ${ }^{19}$ familia toda de condición mulata. Etnia que compartía con sus vecinos, ${ }^{20}$ entre quienes se encontraban también algunos parientes. ${ }^{21}$ Así, en el censo de 1778 se registra, en la nómina de habitantes próximos a la casa de Roque, a Francisco de Lamar, de 49 años, junto a su esposa Basilia Cabrera, de 46, sus dos hijas y una esclava. ¿Eran Francisco y Basilia los padres de Roque? La falta de otra documentación para constatar este vínculo solo nos permite suponerlo. En otra vivienda contigua a la casa de Roque vivían Francisco Olivera, de 39 años, y Rudecinda de Lamar, de 28 años, y sus cinco hijos menores. En las casas que siguen habitaban familias de apellido Suárez, también mulatos y posibles parientes de María Josefa, la esposa de Roque.

La condición étnica no es materia menor en una sociedad como la colonial, fundada en categorías socio-étnico-jurídicas donde las personas clasificadas como españolas ${ }^{22}$ se situaban en la cúspide de una pirámide social que tenía a indios, negros y mulatos en la base; estos, junto a la población mestiza, venían a conformar el sector denominado de castas. Las fuentes censales permiten aproximarnos a estas categorías socioétnicas que deben, sin embargo, ser problematizadas, pues los datos proporcionados por los empadronamientos y registros parroquiales reflejan construcciones intelectuales de los empadronadores, aunque sí podemos pensar que eran categorías socialmente compartidas. ${ }^{23}$ Este modelo estratificado y jerarquizado fue una construcción jurídica e ideológica — de factura peninsular pero que resultó en una pirámide social de características originales- en la que las variables de raza, etnicidad, clase y género interactuaron para determinar el lugar que cada cual ocupaba en la estructura social. ${ }^{24}$ Estas desigualdades socio-étnicas se manifestaban, por ejemplo, en la dispar aplicación de

19 Aunque en su declaración Roque no se explaya sobre su progenie, sabemos por el censo de 1778 que eran tres niñas: Asención [sic] de seis años de edad al momento del censo, María de cuatro y Juana de uno. Censo de Córdoba, 1778, Archivo Histórico de la Provincia de Córdoba, Argentina (AHPC), disponible en https://familysearch.org [consultado: 15/10/2020].

20 Tanto en el censo de 1778 como en el de 1813, la casa de Roque Lamar está registrada próxima a otras cuyos habitantes fueron registrados también como mulatos. Censo de Córdoba, 1778, AHPC, disponible en https://familysearch.org [consultado: 15/10/2020]. Censo de Córdoba, 1813, AHPC, según la base de datos de Arcondo, 1995 (revisada y ampliada por Sonia Colantonio y equipo).

21 La familia Lamar habitaba, según el censo de 1778, cinco casas colindantes identificadas con los números 162, 163, 170, 171 y 172. Carbonari, 2003, 44-45.

22 Como bien señala Lockhart, la cúpula de la sociedad era denominada española en lugar de «blanca», término que raramente aparece en el lenguaje popular u oficial. Lockhart, 2000.

23 Boixadós y Faberman, 2009, 88

24 Presta, 2000, 82-83. 
castigos según la calidad étnica y condición jurídica de la persona; en el parcial acceso que tenían las castas a cargos públicos, religiosos y militares; en las limitadas oportunidades de educación; en las restricciones para ejercer determinados oficios y las prohibiciones en el uso de ciertos adornos y prendas de vestir.

A pesar de los intentos segregacionistas del diseño social original de la América española, en la que formas clasificatorias pretendían dar cuenta de estratos sociales definidos y estáticos, la realidad es que las mezclas entre españoles, indios y africanos fueron intensificándose con el tiempo y, hacia finales del siglo XVIII, el mestizaje llega a ser un hecho indiscutible y en franco avance. En este orden de cosas, cabe señalar que las categorías étnicas fueron de carácter situacional, esto es, en las regiones periféricas - como el espacio fronterizo que nos ocupa- las estructuras sociales fueron más laxas, ${ }^{25}$ permitiendo posibles márgenes de «blanqueamiento» y ascenso social a partir de uniones interétnicas formales o informales. En este marco podemos leer el matrimonio que contrae la hija mayor de Roque en $1809,{ }^{26}$ Asención, con un hombre de condición social superior, don José Anselmo Pizarro, como un acontecer que marcaría una mejora, al menos simbólica, en la condición social de la familia de Roque de Lamar.

El crecimiento demográfico de las castas — que para 1778 comprendían más de la mitad de la población de la provincia de Córdoba— ${ }^{27}$ fue determinante en el recrudecimiento del prejuicio racial. ${ }^{28}$ Ello contribuyó, a su vez, a conformar la imagen del pardo, el negro y el mulato como representantes de lo ilegítimo, de la «mala raza» y lo desviado, rasgos vinculados a prácticas censurables como la vagancia, el mal entretenimiento, el juego y el amancebamiento. Conductas que se constituyen en objeto de los mecanismos de control y disciplinamiento social que se intensifican y cobran notoria relevancia a partir de las Reformas Borbónicas, especialmente, hacia finales del Setecientos. ${ }^{29}$

25 Farberman y Ratto, 2009.

26 Matrimonio de José Anselmo Pizarro con Asención de Lamar, Río Cuarto, 3 de febrero de 1809, Archivo del Arzobispado de Córdoba, Libro de Matrimonios, Río Cuarto, Catedral de la Inmaculada Concepción. Disponible en https://familysearch.org [consultado: 15/10/2020].

27 El empadronamiento de $1778-1779$ arroja un total de 20.101 españoles o blancos y 23.410 personas del sector de castas. Celton, 1993, 27.

28 Endrek, 1966.

29 Señala Darío Dominino Crespo, para el ámbito urbano, que la «gente plebe» de la Córdoba de finales del siglo XVIII fue el grupo social que sufrió el peso de la ley más que otros sectores. Dominino Crespo, 2007. 
En cuanto a su oficio, Roque declara ser carpintero, actividad con que se mantenían tanto él como su familia. Sin embargo, años después, en el censo de 1813, será registrado como labrador. ${ }^{30}$ Lo cierto es que, durante el proceso y desde hacía un tiempo considerable (tres años y cuatro meses), ${ }^{31}$ Roque afirmaba no dedicarse a la carpintería, ejerciendo, en cambio, prácticas curativas, autorizadas, según dijo, por el cura vicario. Conforme a su declaración y la documentación respaldatoria que presenta, el cura Santiago Arias de Cabrera le había otorgado licencia para curar debido a la cantidad de «enfermedades y enfermos» que había en la zona y a la escasez de facultativos. ${ }^{32}$

Si de la moral del acusado se trata, se añadirá que Roque era un «famoso ladrón y perseguido de la justicia», ${ }^{33}$ que había robado seis vacas a doña Juana Correa, una mujer de la zona. Se dijo, además, que el acusado era persona de «malas costumbres», que incluso «tubo el atrevimiento de querer violentar a la mujer de Narciso Luzero [...] siendo señora de las principales de aquel partido». ${ }^{34}$ Replica Roque a esta acusación que él solo la «avia aporreado dándole uno u otro golpe con las manos y los pies en todo el cuerpo, aunque no en la cara», ${ }^{35} \mathrm{y}$ con respecto al robo de vacas, asegura que ya tenía satisfecho el valor de las mismas. No será la primera vez que se acusa a Roque de robo de hacienda, pues en 1794 se le inicia sumaria por hurtar algunas ovejas al juez pedáneo Joaquín de Bengolea y desfigurarlas con otra señal; acción que, aparentemente, había practicado también con la tropilla de otra vecina del lugar. ${ }^{36} \mathrm{El}$ abigeato era, para la época, un delito bastante extendido. Más aún, hacia finales del siglo XVIII, se observa un considerable incremento en el número y frecuencia de expedientes por robo de cuatropea. Como bien señalaron Punta, ${ }^{37}$ Rufer $^{38}$ y Alessandroni y Rustan, ${ }^{39}$ ello no supone un aumento lineal de los actos delictivos ni la criminalización de prácticas antes permitidas. Antes bien, da cuenta de un

30 Censo de Córdoba, 1813, AHPC, según la base de datos de Arcondo, 1995 (revisada y ampliada por Sonia Colantonio y equipo).

31 Causa contra Roque de Lamar por curandero, Córdoba, 1789, AHPC, Crimen, leg. 48, exp. 3, f. 12 .

32 Ibidem, f. 10.

33 Según certifica don José Antonio González, capitán de Partidarios y ayudante de Frontera. Causa contra Roque de Lamar, por curandero, Córdoba, 1789, AHPC, Crimen, leg. 48, exp. 3, f. 2.

34 Ibidem, f. 4.

35 Ibidem, f. 8v.

36 Sumaria contra Roque de Lamar, Córdoba, 1794, AHPC, Crimen, leg. 62, exp. 8.

37 Punta, 1997 y 1999.

38 Rufer, 2001 y 2005.

39 Alessandroni y Rustán, 2001. 
cambio en los procedimientos de administración de la justicia y la puesta en marcha de un aparato que busca dotar de un marco legal situaciones que ya venían ocurriendo hacía tiempo. Algunos números echan luz sobre el peso estadístico de este tipo de delitos: entre 1776 y 1808 , el $42 \%$ de los procesos se realizaron por causas vinculadas a delitos contra la propiedad. ${ }^{40}$ Si hacemos foco en los expedientes criminales que tienen a mulatos o negros como acusados, llegamos a proporciones muy similares: el $41 \%$ de los delitos registrados corresponde a robo o hurto, categoría dentro de la que destaca, a su vez, el robo de cuatropea o hacienda. ${ }^{41}$

Como bien sabemos, Roque es procesado por curandero o «médico intruso» luego de asistir a un enfermo al que le aplica diversos remedios que terminaron, según testigos, por provocar la muerte del doliente: el comandante Juan Gualberto Soria, un personaje relevante en la vida política y militar de la frontera sur de Córdoba. Su padre, el sargento mayor Ignacio de Soria y Medrano, había tenido a su cargo, desde mediados del siglo XVIII, la custodia de la frontera del Río Cuarto, y hacia 1786 es al propio Juan Gualberto Soria a quien se le asigna la tarea - por parte del gobernador intendente marqués de Sobremonte- de formar el pueblo de la Concepción, en terrenos previamente seleccionados en la banda sur del Río Cuarto. Allí debía disponer el lugar para plaza, calles, ayuntamiento e iglesia, y reagrupar al conjunto de treinta y una familias que, hasta ese momento, habitaban dispersas. ${ }^{42}$ Los Soria formaron parte de la elite local; sector social que concentrara rango, poder y riqueza, compuesto por dos grupos principales: los descendientes de los conquistadores - con presencia desde el siglo XVI- y los primeros pobladores con asiento en la zona en los siglos XVII y XVIII. ${ }^{43}$ La familia de Juan Gualberto formaba parte del primer grupo. Las familias de elite se vinculaban en diverso grado al sistema socioeconómico y político del mundo colonial cordobés, pero dada la locación geográficamente marginal, el concepto de elite debe tomarse de forma más bien laxa y provisoria. ${ }^{44}$

40 Alejandro Agüero obtiene estos porcentajes sobre la base de 166 expedientes criminales tramitados en ese período. Agüero, 2008. Del mismo modo, Ana Inés Punta obtiene, para el lapso 1785 1790, resultados similares. Punta, 2002.

41 Moreyra obtiene estos porcentajes sobre la base de 105 expedientes criminales que tienen al menos a un negro o mulato como acusado o víctima de delito, tramitados entre 1783 y 1797 . Moreyra, $2020,23$.

42 «Sobremonte funda el Pueblo Fuerte de la Concepción», Córdoba, 11 de noviembre de 1786, AHPC, Escribanía 3, leg. 52, exp. 7. Citado por Montes, 1953, 47.

43 Carbonari y Baggini, 2004.

44 Idem. 
El vínculo de Roque con la familia Soria precede al episodio de la enfermedad y muerte de Juan Gualberto, pues, hacía cuatro años, la madre del comandante, doña Juana Correa, puso demanda contra Roque de Lamar por haberle robado, en compañía de otra persona, seis vacas que luego trasladó hacia San Luis. ${ }^{45}$ Ahora bien, este episodio cuenta con un actor fundamental en el desenlace de los acontecimientos: llevando los animales robados hacia otra localidad, Roque es apresado. Es entonces cuando se presenta el cura vicario del partido, don Santiago Arias de Cabrera, y «se empeña en que lo pongan en libertad», prometiendo «conservarlo conchavado en su poder». ${ }^{46}$ Pero no concluyen aquí los «beneficios» que Roque recibe por parte del cura, pues cuando Narciso Lucero se dirige al cura vicario del Partido para poner demanda contra Roque de Lamar por haber intentado violentar a su mujer, el cura «no le hace justicia», favoreciendo, de este modo, al curandero. Como veremos en las páginas siguientes, el accionar de Arias de Cabrera resulta crucial, también, en el marco del procesamiento por curanderismo, pues, según declara Roque, y acorde a la documentación que presenta, fue el propio cura vicario quien autorizó a Roque a sanar. ${ }^{47} \mathrm{San}-$ tiago Arias de Cabrera y Montenegro, hijo de Juan Luis Arias de Cabrera y Gutiérrez y Bernardina Montenegro, era tataranieto del general Jerónimo Luis de Cabrera III. Estudió en el colegio de Nuestra Señora de Monserrat y en la universidad de San Carlos, donde se recibió de doctor en Teología en 1764. Ejerció como sacerdote en el curato de Traslasierra y luego, trasladado a Río Cuarto, se desempeñó como cura ayudante primero y, desde 1769 , como cura vicario. ${ }^{48}$

Los deponentes de la causa son, al igual que Soria, funcionarios y militares de la frontera. Uno de ellos, el comandante del fuerte de Santa Catalina, don Ventura Echeverría, es un personaje de reconocida familia de la elite local. Oriundo de Buenos Aires, se traslada a Córdoba a mediados del siglo XVIII como mercader tratante y, vinculándose con la estructura de poder, adquiere funciones militares en la frontera sur, específicamente, en Punta del Sauce. ${ }^{49}$ El segundo testigo es el ayudante mayor de Frontera, don José Antonio González, quien se alojaba en la casa de Soria y presenció el día que este «cayó enfermo» y «los de la casa» solicitaron la presencia

45 Causa contra Roque de Lamar, por curandero, Córdoba, 1789, AHPC, Crimen, leg. 48, exp. 3 , f. 4

46 Idem.

47 Ibidem, f. 10.

48 Mayol Laferrère, 1980, 23. Citado por Carbonari y Baggini, 2004.

49 Carbonari y Baggini, 2004. 
del «médico intruso» Roque de Lamar. La expresión «los de la casa» podría incluir a la esposa de Soria, doña Pascuala Ojeda, natural de San Luis y, acaso, a la madre del enfermo, doña Juana Correa.

La revisión del documento muestra, en síntesis, la mixtura y contacto entre sujetos que se encontraban en la cima y en la base de la pirámide de la sociedad colonial del espacio considerado, como también el resquebrajamiento de cierto grado de legitimidad con el que contaba el protagonista de nuestra historia a partir de un infortunio.

\section{La acusación. Los argumentos de defensa}

Los testigos referidos en el apartado previo — de jerarquía destacada - prestan declaración arremetiendo con efervescencia contra Roque de Lamar. De acuerdo a lo relatado por los subalternos de Soria, el mulato fue solicitado ante el malestar de su superior y, luego de tratarlo, este habría muerto al día siguiente. De manera directa, los testigos coincidían y remarcaban que aquel fallecimiento era la causa del fracaso de las prácticas perpetradas, ancladas en supersticiones y desconocimientos; en los hechos, ambos partían de reconocer que De Lamar no sabía certeramente a qué dolencia se enfrentaba: «le preguntaba que mal le parecía hera el que le afligía al comandante nunca daba razón que sirviese de alguna satisfacción». ${ }^{50} \mathrm{Sin}$ embargo, pese a no conocer (en apariencia) cuál era el origen de la enfermedad - aventurando González que se trataba de un fuerte resfrío-, Roque habría ejecutado su praxis:

abiendo visto al enfermo luego de incontinente conpuso un sebo con totora quemada (semejante al que dan a los Ejes y masas de las carretas) y con el le dio una uncion en el cuerpo de sintura abajo; y al siguiente dia hallándose dicho enfermo con una fiebre ardientísima trajo el citado medico un as de ojas de lampason y bañando estas con agua elada con ellas le emorbio de medio cuerpo arriba y a la sason estaba el enfermo en una flución de sudor de la punta del pecho a la cabeza [...] y para mas agrabar el accidente le emborbio al paciente la cabeza con balletas calientes y umadas con los palos de yerba quemado [...] esta tercera operación el desasierto de un rebato de sangre que ynstantaniamente se berifico por la mucha que fluio dicho enfermo por las narices..$^{51}$

50 Causa contra Roque de Lamar, por curandero, Córdoba, 1789, AHPC, Crimen, leg. 48, exp. 3 , f. 1

51 Ibidem, f. 2. 
Esta locución proporciona algunas pistas acerca de un intersticio clave de nuestro estudio: el vínculo entre Roque y el cura vicario de la zona. Como mencionamos anteriormente, este último le habría otorgado al reo una suerte de permiso para llevar a cabo prácticas beneficiosas y, en sus propias palabras, consideraba que estas eran suficientes para poder curar la peste introducida y «algún otro achaque». ${ }^{52}$ En otros términos, pese a las diatribas de Ventura Echeverría y González respecto a los perjuicios que podría ocasionar la actividad de Roque «en los vivientes racionales de estas fronteras a quienes dicho mulato tiene engañados con sus sofisterías y marañas», ${ }^{53}$ una imponente figura del entramado social de Río Cuarto consideraba que Roque poseía ciertas aptitudes para resolver vicisitudes en el ámbito de la salud. Ahora bien, las descripciones del procedimiento aplicado sobre Soria exhiben un rasgo insoslayable: se encontraba anclado en elementos naturales tales como las totoras, ${ }^{54}$ hojas de lampason, ${ }^{55}$ agua fría y palos de yerba. Roque se valía, entonces, de las propiedades de la flora del lugar y no de otras creencias —al menos no de manera explícita— para atender a los dolientes. Conjeturamos que esta arista de sus prácticas resultó esencial para que la relación entre el mulato y el cura vicario prosperase. En efecto, como señala la bibliografía especializada, otras actividades que implicaran la búsqueda de sanación mediante ciertos procedimientos considerados heréticos por la Iglesia — encarnados en brujas y hechiceras- fueron cabalmente cuestionados y arrastraron anatemas. ${ }^{56}$ En contraposición con ellas, los quehaceres fundamentales de los curanderos consistían en la sanación mediante prescripción de hierbas, pues enfatizaban que no había ninguna que careciera de alguna virtud curativa. ${ }^{57}$

Otra de las informaciones que aporta la declaración de Santiago Arias de Cabrera y Montenegro acerca de la aquiescencia que le brindara a De Lamar nos remite a la falta de médicos diplomados, argumento que sería retomado por el abogado defensor. Ingresando en su alegato, reconocemos algunos puntos esenciales acerca del binomio salud/enfermedad de la época, como también la existencia y puesta en marcha de estrategias por parte

52 Ibidem, f. 10.

53 Ibidem, f. 2.

54 Se trata de gramíneas utilizadas en la zona para la confección de canastos.

55 También conocida como bardana, el lampazo es una hierba utilizada ante problemas urinarios, piel, hígado, vesícula, intestinos y tumores.

56 Aspell, 2007. Farberman, 2010. Vasallo, 2015.

57 Bubello, 2010, 31. 
de Roque para posicionarse en un mercado terapéutico, estando en la mira del ojo público.

En primer término, el letrado aseveraba estar al tanto de las leyes relativas al ejercicio de la «medicina, cirugía, pharmacia y phlevotomias». ${ }^{58}$ En efecto, bien era sabido que la legislación no permitía curar a quienes no fuesen galenos aprobados - fundamentalmente a partir del año 1780 — por el Real Protomedicato, institución colonial encargada de regular el arte de curar, a cuya cabeza se encontraba el doctor Miguel Gorman, nombrado por el virrey Juan José de Vértiz y Salcedo. ${ }^{59}$ En el marco de las Reformas Borbónicas, es factible advertir que este ente tenía como finalidad «controlar la práctica médica profesional, la protección de la salud pública y la enseñanza de la ciencia médica». ${ }^{60}$ Considerando un concierto aún más amplio, es dable destacar que el «siglo XVIII es presentado como el centro medular de la "evolución" de la medicina: la "razón" que derrota con sus "luces" las prácticas populares de carácter "mágico" y las concepciones filosóficas de orden médico». ${ }^{61}$ Ciertamente, la investigación empírica y la naciente clínica se abrieron paso en el campo de la tradición médica clásica; no obstante, el caso bajo estudio muestra la presencia de trayectorias de enfermos que no arribaban, necesariamente, a las puertas de expertos certificados.

Para el espacio abordado, la crónica escasez de médicos diplomados fue una constante y la vigilancia estricta se tornaba imposible en un territorio tan vasto. El censo de 1813 da cuenta de ello: en villa de la Concepción se registra un solo médico (de origen francés) y para la ciudad de Córdoba, cuatro (entre los cuales sólo uno era oriundo de dicha urbe).$^{62}$ Estos datos numéricos respaldan el discurso del jurista en torno a la desprotección de los pobladores de la zona ante las magras posibilidades de atenderse con un médico aprobado y certificado por el Real Protomedicato. Considerando esta situación en que «la necesidad carece de ley», ${ }^{63}$ y ponderando la importancia del rol de Roque en su comunidad, argüía: «seria un error bien

58 Resolución sobre restricción por abusos y desarreglos con que ejercitan la medicina, cirugía, farmacia y flebotomía. «El virrey informa al gobernador de la creación del Tribunal Real del Protomedicato para controlar abusos en el ejercicio de la medicina, cirugía y farmacopea», Córdoba, 1780, AHPC, Gobierno, t. 6, leg. 79, carpeta 5, f. 1.

59 Véase Macagno, 2011.

60 Bubello, 2010, 49.

61 Amodio, 1997, 96.

62 Censo de Córdoba, 1813, AHPC, según la base de datos de Arcondo, 1995 (revisada y ampliada por Sonia Colantonio y equipo).

63 Causa contra Roque de Lamar, por curandero, Córdoba, 1789, AHPC, Crimen, leg. 48, exp. 3 , f. 13 . 
perjudicial extender aquella prohibición al caso de necesidad [...] El Rey que en toda su legislación siempre ha tenido por objeto el bien de sus basallos nunca ha pensado en privarles del alivio de buscar quien les cure en sus necesidades y dolencias quando no [hubiera] médicos aprobados». ${ }^{64}$ La apelación a la figura de máxima autoridad para la región —el soberano real一, como también al «Derecho Natural de conservación de la vida» ${ }^{65}$ para justificar el accionar del mulato, son herramientas instrumentadas por la defensa.

Dentro de esta exposición que realza la falta de médicos subyace otra consideración no menor: «[Roque] se ha dedicado [a] los enfermos en unos lugares que no solamente carecen de facultados, pero tampoco se encuentran curanderos ni de mayor o menor crédito que él» ${ }^{66}$ Este testimonio nos conduce a una interrogación acerca de la existencia de categorías de sanadores en un mercado terapéutico rural. De acuerdo a otros pasajes del documento, que muestran términos como «chusma» $\mathrm{o}$ «charlatanes», intuimos que esos sujetos que estarían por debajo del status del acusado - de acuerdo a las expresiones de su abogado - serían aquellos identificados a partir de un espíritu especulativo y mercantil.

A partir de allí ingresamos en el segundo punto que justificaría las labores del mulato: «no ha tomado esta ocupación con el fin de atesorar ni aun de lucrar cosa alguna, pues de todo el proceso no consta haya pedido un real a los que ha curado». Este argumento se torna un tanto discordante, fundamentalmente considerando que Roque declaró haber estado dedicándose solo al arte de curar - y de manera absoluta desde hacía largo tiempo- al momento del incidente por el que se lo acusa. De haber sido así, nos preguntamos por los recursos con los que el reo contaba para solventar a su familia. Intuimos que es factible que no existiese, a priori, una tarifa establecida, sino que es posible que su «clientela» le pagara de manera voluntaria y no con dinero, pero sí con animales, comida u otros servicios. Cabe recordar, además, que De Lamar expuso ejercer en otros tiempos el oficio de carpintero y años después (según el censo de 1813) el de labrador; verosímilmente, estas actividades eran complementadas, al menos por momentos, con las curativas que, de acuerdo con la declaración del mismo Roque, en el caso de Soria implicaran «agua caliente con gajos de sauce y poleo $[. .$.$] cebollas blancas molidas», además de la puesta en práctica de$ 
ciertas destrezas como las fricciones y sangrías. ${ }^{67}$ Es decir, el tratamiento por él realizado no involucraba la utilización de materiales costosos. Sin embargo, el hecho de que no cobrara (en metálico) también podría aunarse al lugar que él ocupaba en la sociedad de la cuál formaba parte. En este paraje lejano, fronterizo, el acusado era detentor de ciertos conocimientos que aplicaba sobre quienes acudían a él en busca de ayuda. De modo que la «rustiques y [el hecho] de haberse criado únicamente en ejercicios de campo ${ }^{68}$ no eran en general, para sus vecinos e incluso para gentes encumbradas del lugar, elementos de peso para preferir la atención de la salud con un diplomado que, como hemos visto, era foráneo. Es posible, entonces, que en esa comunidad existieran ciertos lazos de amistad, de cercanía y confianza que aproximaran a este «anfibio» con múltiples sujetos del conjunto social a quienes él decidía no pedir retribución. Esta lógica también puede ser leída en términos de estrategia por parte de Roque, pues sus actividades transcurrían en un escenario en el cual ya existía una preocupación estatal por alejar a la población de los curanderos.

Finalmente, y en estrecha vinculación con el entramado socio-comunitario revisado, arribamos a la tercera premisa esgrimida: «erradamente se le acusa haberse figurado medico [...] el mismo publicaba que toda su instrucción se reducia al conocimiento de cuatro remedios caseros adquirido con la experiencia». ${ }^{69}$ Este rasgo, la supuesta falsedad del criminal, surca múltiples folios del expediente; por momentos, Roque es presentado como un embaucador que «se ha introducido de médico en esta dicha frontera haciendo creer a las gentes que le acompaña una grande intelijencia y hacierto en sus curaciones», ${ }^{70}$ mientras otras veces se habla de él como «medico [...] tan perjudicial a estos lugares que se le debe privar de ello». ${ }^{71}$ La supuesta no presentación del mulato como médico a la que hace alusión el letrado - es decir, el reconocerse como no poseedor de títulos universitarios - también puede ser vislumbrado como una táctica para evadir los canales de la justicia.

Lo cierto es que la legitimidad social del acusado (visible a partir de que es «aceptado en la opinión de nuestras gentes de esta frontera») $)^{72}$

67 Causa contra Roque de Lamar, por curandero, Córdoba, 1789, AHPC, Crimen, leg. 48, exp. 3 , f. 8

68 Ibidem, f. 1.

69 Ibidem, f. 14.

70 Idem.

71 Ibidem, f. 2.

72 Ibidem, f. 1. 
deviene cuestionada por individuos pertenecientes a los sectores acomodados de villa de la Concepción solo a partir de la muerte del comandante Soria. Empero, y como veremos a continuación, este suceso - junto con otros de carácter delictivo en los que De Lamar estuvo implicado- no determinó que continuara privado de su libertad.

\section{Resolución de la causa}

La causa contra Roque de Lamar tiene lugar dentro de un marco de intensificación de la voluntad de control social por parte del poder político: accionar manifiesto en un conjunto de mecanismos tendentes a centralizar la administración de justicia. ${ }^{73}$ La designación de nuevos funcionarios - como los jueces pedáneos, encargados de fiscalizar el orden e impartir justicia en la campaña - y el crecimiento del número de expedientes criminales - en comparación con períodos anteriores - son elementos constitutivos de esa intencionalidad de formalizar prácticas que antes no se registraban y poner término a los dispositivos extrajudiciales y privados de aplicación de castigos. La frontera sur de Córdoba, espacio vasto, con una población dispersa y móvil, será, acaso, territorio propicio para la diversidad de ilegalismos y, por ello, será también un ámbito donde el imperativo de vigilancia sobre los sujetos se vuelva más acuciante.

El procesamiento por curanderismo ejecutado contra De Lamar es el único identificado para la región y el período; ello no significa que las prácticas curanderiles fueran excepcionales o nuevas; el caso tampoco supone que un accionar de este calibre fuese permitido antes y, a partir de ese momento, criminalizado y condenado. Más bien, este proceso se situó en un escenario signado por nuevos procedimientos judiciales y cobró especial visibilidad por haberse producido una muerte que, detalle fundamental, fue la de una persona destacada dentro del conjunto social de la región. El aparato legal que se pone en funcionamiento para otorgar un marco institucional al castigo se observa en el proceso contra Roque: es el juez pedáneo quien inicia la sumaria, participan testigos, interviene el gobernador intendente y se dicta sentencia. Esto último adquiere particular relevancia en el período, pues, no solo crece hacia finales del siglo XVIII el número de expedientes criminales como ya mencionamos, sino que también aumenta

73 Punta, 1997; 1999 y 2002. Rufer, 2001 y 2005. Alesandroni y Rustan, 2001. Dominino Crespo, 2007. Dainotto, 2012. Ambroggio, 2013. 
el número de los que terminan con sentencia, decreciendo así la cantidad de procesos que quedan irresueltos. ${ }^{74}$

Agüero señala que los castigos correspondientes para cada tipo de delito no estaban explicitados, no dependían de una estipulación legal concreta y, en virtud de ello, la resolución de las causas quedaba librada al arbitrio del juez, quien podía condenar al reo a recibir azotes, destierro, muerte, presidio, pena pecuniaria, trabajo en cadena y obras públicas, o bien, libertad a condición de conchabo. En general, las penas más usuales eran los azotes, el destierro y los servicios. ${ }^{75}$ Esta idea debe ser matizada pues, como revelan los cuerpos legales vigentes para la época, cada figura delictiva tenía — en la mayoría de los casos — una pena establecida. Sin embargo, bien es sabido que los jueces no realizaban una aplicación directa y mecánica de ellas, ya que gozaban del «arbitrio judicial» para proceder según el caso que debían resolver y sus condiciones generales de comisión.

Quienes testifican contra Roque describen, como bien se dijo, los remedios que este aplica, los cuales, según la perspectiva de los declarantes, eran equivocados y contradictorios, sobre todo considerando que el mulato no habría logrado identificar la dolencia que aquejaba a Soria. Aquí conviene no perder de vista, por un lado, que el presunto criminal expresaría algo diferente: le realizó dos sangrías, «pues tenía dos achaques, el uno de una aflición de estomago de que adolecía en sana salud y el otro de la peste de que cayó enfermo sin que le suministrase algún otro remedio». ${ }^{76}$ Asimismo, asegura que el enfermo falleció seis o siete días después de que lo atendiera. Es decir, su discurso estaría en las antípodas del de los testigos. Por otro lado, resulta insoslayable que los declarantes eran dos sujetos cuyas tareas se hallaban vinculadas al universo militar, hecho que sirvió de instrumento al abogado defensor: no tenían instrucción alguna en el arte de curar y, por ende, no podían conocer el mal que aquejaba a su superior, como tampoco la efectividad de los medicamentos aplicados por Roque. ${ }^{77}$

Retomando el eje de las puniciones, destacamos que el testigo Ventura Echeverría sugiere que se debe privar al médico intruso de seguir ejerciendo sus prácticas curanderiles, además de ser «castigado con destierro», ${ }^{78}$ aludiendo, de este modo, a una de las penalidades más frecuentes,

74 Ambroggio, 2013. Punta, 1997. Rustan, 2005. Vassallo, 2006.

75 Agüero, 2008, 262.

76 Causa contra Roque de Lamar, por curandero, Córdoba, 1789, AHPC, Crimen, leg. 48, exp. 3 , f. 8

77 Ibidem, f. 14.

78 Ibidem, f. 2 
particularmente relevante para la región lindante en que se encontraban, pues el destierro era - como pena aplicada a vagos, malentretenidos, amancebados y ladrones de ganado - un instrumento crucial dentro de la política de poblamiento de la frontera. ${ }^{79} \mathrm{El}$ otro testigo, por su parte, propone que se le imponga al acusado «todo el rigor de la ley» para prevenir que otras personas cometan semejante delito. Su mirada apunta al castigo ejemplificador que, como tal, debía suponer una ejecución pública, es decir, la espectacularización del castigo que satisfaga la vindicta pública.

Con todo, más allá de los castigos sugeridos por los declarantes - cuestión que, cabe señalar, no estaba entre las atribuciones del testigo- es el gobernador intendente quien dicta la sentencia final, estableciendo que la cárcel que ya había sufrido Roque era suficiente corrección; resolviéndose, entonces, que sea puesto en libertad, pagando las costas correspondientes y bajo el apercibimiento de no volver a incurrir en tales prácticas curativas ya que, de lo contrario, sí sufriría entonces todo el «rigor de la ley». Asimismo, se previene al cura vicario «se abstenga de inculcarse en cosas tan estrañas a su jurisdicción, como las facultades que al parecer confirió al reo». ${ }^{80}$

Se ha señalado que la condición étnica era un factor determinante en la aplicación del castigo, pudiendo los españoles recibir, a iguales delitos, penas más benignas que el común de la población. Esto eximía a los sectores privilegiados de ser castigados con azotes y vergüenza pública; en lugar de tales penas eran, por ejemplo, impelidos a pagar fianza o multa. Incluso, como consta en Las Partidas de Alfonso X, si «el hidalgo» merecía la muerte, esta no debía ser ignominiosa o humillante.$^{81}$ La práctica era, sin embargo, más compleja. Sirva de muestra el caso del mulato Mathias Basan, acusado de robo de hacienda, quien no es penado con azotes como era la tónica general en estas situaciones. Tal desenlace resultó posible gracias a la red de relaciones que le posibilitaron su libertad a través del pago de fianza. ${ }^{82}$

La sentencia que recibe Roque de Lamar orienta este caso en sintonía con el anterior, jalonando el interrogante en torno a la incidencia de la red vincular del acusado en la resolución de la causa que le permitió, en definitiva, librarse de otro tipo de castigos que, acorde a su condición étnica,

79 Rustán, 2005.

80 Causa contra Roque de Lamar, por curandero, Córdoba, 1789, AHPC, Crimen, leg. 48, exp. 3, f. 19

81 Levaggi, 1978, 56.

82 Fernández Asencio contra Mathias Bazan por robo de mulas, Córdoba, 1791, AHPC, Crimen, leg. 53, exp. 21. Citado por Alessandroni y Rustán, 2001, 28. 
pudiera haber recibido. Así pues, cobra relevancia la figura del cura vicario Santiago Arias de Cabrera, quien, como ya señalamos, autorizó a Roque a realizar sus prácticas curativas amparándose en la ausencia de facultativos en la zona. Más aun, este funcionario eclesiástico ya había favorecido a Roque en otras ocasiones: insistió en su libertad cuando lo imputaron por robo de ganado y en otra oportunidad hizo oídos sordos a la denuncia por violación que se puso contra De Lamar.

El vínculo entre Roque y el sacerdote es evidente, tanto como innegable es el papel clave que jugaran los eclesiásticos en el esquema del poder colonial. Las disposiciones del Concilio de Trento se orientaron a reafirmar y reactivar el papel de los sacerdotes en la sociedad, convirtiéndose estos en verdaderos líderes de la comunidad, especialmente, en aquellas extensas tierras alejadas de los centros de poder político. ${ }^{83}$ Así, aunque el cura Arias de Cabrera no contaba con autoridad para licenciar en el oficio de médico - algo que solo podía autorizar el Tribunal del Protomedicato o la Santa Inquisición-, es factible que, en la práctica, y dado el lugar que ocupaba como figura de autoridad en la región, el conjunto social le adjudicara, de facto, prerrogativas que en la ley no tenía; y por ello, las personas, como fuera el caso de Narciso Lucero, acudían a él en busca de justicia en lugar de hacerlo con el juez pedáneo. Que el cura autorizara a Roque de Lamar a ejercer como médico se inserta, entonces, en el marco de las múltiples tensiones existentes entre el poder eclesiástico y el político, más aun, en pleno auge de las Reformas Borbónicas, cuando la Monarquía buscaba afianzar su control sobre la sociedad, dominio que debía primar ante cualquier otra autoridad, especialmente la del orden religioso. De modo que cobra sentido que en la sentencia dictada por el gobernador intendente se reforzara el impedimento que pesa sobre Arias de Cabrera en lo que atañe a expedir autorizaciones para el ejercicio de labores, como, por ejemplo, el de curar.

Entre los sujetos que toman parte en la causa contra De Lamar está el colectivo, algo impreciso, por cierto, que hemos de llamar «la comunidad». Su intervención es, sin embargo, difusa y tangencial, pues nunca oímos aquellas voces de primera mano, sino que son los testigos que declaran sobre la enfermedad y muerte de Soria y el juez pedáneo quienes toman el lugar de «las gentes» de la zona y hablan por estas. ¿Qué vínculo tenía, pues, Roque con esa comunidad y qué concepto tenía esta sobre aquél? Como se ha dicho en la sumaria sobre el caso, el juez pedáneo asevera que Roque

83 Irigoyen López, 2012. 
hacía «creer a las gentes que le acompaña grande inteligencia y acierto» $\mathrm{y}$, por ello, es «solicitado para curar» ${ }^{84}$ De allí que requiriese a los testigos se expidan sobre si «es cierto que el expresado Roque de Lamar esta hadmitido por médico aceptado en la opinión de nuestras gentes de esta frontera y que en esta creensia le solicitan para qurar todos dolores de accidentes». ${ }^{85}$ A ello responderá el testigo Echeverría que tiene noticia que por aquel lugar «es medico el mulato Roque de Lamar que ha poco ha tomado este exercicio», ${ }^{86}$ práctica que era factible ejecutar dada la «credulidad que estas gentes tienen». ${ }^{87}$ Por su parte, el segundo testigo manifestará que dicho mulato ha mentido y engañado, siendo «lo más de su vida un famoso ladrón». ${ }^{88} \mathrm{La}$ tensión entre legalidad y legitimidad es notoria, pues a partir de los testimonios resulta claro que la gente de la zona acudía a Roque para valerse de sus saberes y prácticas a la hora de curar sus dolencias. La legitimidad que emerge de la praxis de la comunidad que toma a Roque como médico y a él acude cuando tiene alguna enfermedad es traducida por los testigos como el mero efecto de los engaños de Roque en combinación con la credulidad de la gente. Sin embargo, como muestra Garcés, ellos mismos —autoridades militares del fuerte y personas encumbradas de la región - confiaron en el curandero para atender a su comandante; es decir que, a priori, su capacidad era reconocida. ${ }^{89}$

La totalidad de la prueba de la causa se construyó a partir de esas declaraciones testimoniales y, para la cultura jurídica de la época, lo expresado por dos testigos de visu (en este caso, Echeverría y González) resultaba suficientemente probatorio. ${ }^{90}$ No obstante, dadas las repetidas referencias a «la gente» del lugar y su «credulidad» para con los saberes médicos de Roque (además de las alusiones a la, en apariencia, conocida conducta delictiva del acusado) podrían haberse incluido los testimonios de vecinos del lugar que dieran cuenta «de vistas u oídas» del accionar de Roque como «conocido ladrón»o «médico intruso». La multiplicación de testimonios que se advierte en otras causas y están ausentes en esta, coadyuvaban en la construcción del hecho, pero también en la composición de una imagen

84 Causa contra Roque de Lamar, por curandero, Córdoba, 1789, AHPC, Crimen, leg. 48, exp. 3 , f. 1 .

85 Idem.

86 Ibidem, f. $1 \mathrm{v}$.

87 Ibidem, f. 2.

88 Ibidem, f. $2 \mathrm{v}$.

89 Garcés, 2010, 17.

90 Agüero, 2008, 344. 
del reo que era no solo la que tenía el testigo, sino, al invocar la «pública voz y fama», era también una imagen que la sociedad había construido en torno al acusado, su forma de vida, su accionar, en definitiva, su naturaleza. Como señala Farberman, «la circulación de rumores, las eventuales denuncias o la descripción pormenorizada de los hechos reales o imaginarios que nutrían las informaciones sumarias tenían un peso por demás significativo y le otorgaban al público un papel determinante en el proceso». ${ }^{91}$ La fuente bajo estudio carece de esta pieza clave de la historia, del imaginario de los sectores no acomodados de la sociedad en torno a Roque.

\section{Consideraciones finales}

El presente estudio ha tenido por objeto examinar los posicionamientos y estrategias de Roque de Lamar, un mulato acusado de curandero en la Córdoba de fines del siglo XVIII, tras la muerte de una figura prominente de la región. Hemos partido de considerar la existencia de cierta dualidad en este caso; por un lado, el acusado era parte del conjunto de castas y se hallaba en las afueras de la medicina diplomada. En otros términos, sus faenas no estaban dentro de los límites de la legalidad y la legitimidad otorgadas por la Monarquía. Por otro, se encontraba al resguardo del cura vicario de la región desde hacía tiempo y contaba con la aprobación de la comunidad en la cual transcurría su vida.

El expediente judicial que contiene la demanda a Roque nos ha permitido reconstruir - mediante ciertos indicios - una pequeña historia. Tomando como puntapié inicial la muerte del comandante Soria, como consecuencia (en apariencia) de las prácticas curativas no alopáticas ejercidas por el acusado, hemos indagado en su universo familiar más cercano, en sus redes vinculares y en el posicionamiento de los testigos —en contra de Roque-, ponderando su pertenencia a sectores sociales encumbrados. También ingresamos en los argumentos que justificaban el accionar del mulato - los del cura vicario y el defensor-, tales como la falta de médicos, su motivación alejada de cualquier tendencia lucrativa y el hecho de que no se presentaba como médico.

Estas tensiones y configuraciones fueron leídas a la luz del escenario macro de las Reformas Borbónicas, a partir de una búsqueda de un mayor

91 Farberman, 2005, 91. Véase Ambroggio, 2013; Rufer, 2005; Vasallo, 2006. 
control sobre la población del virreinato por parte de la Corona Española. Allí, el campo de la salud y la enfermedad sería custodiado por el Real Protomedicato. Sin embargo, el caso bajo estudio da cuenta de las limitaciones de esta entidad en el vasto territorio de la gobernación del Tucumán, como también de las destrezas de los pobladores para evadir ciertas penas impuestas por la justicia.

Recibido, 17 de junio de 2020 Segunda versión, 16 de octubre de 2020 Aceptado, 17 de noviembre de 2020

\section{Referencias bibliográficas}

Agüero, Alejandro, Castigar y perdonar cuando conviene a la República. La justicia penal de Córdoba del Tucumán, siglos XVII y XVIII, Madrid, Centro de Estudios Políticos y Constitucionales, 2008.

Alessandroni, Gabriela y Rustán, María E., «La aplicación de la justicia en la campaña, Córdoba, 1785-1790», Cuadernos de Historia. Serie Economía y Sociedad, 4, Córdoba, 2001, 11-37.

Ambroggio, Eugenia, Violencia, género y honor en la Córdoba borbónica. Justicia y mecanismos informales de control social, Córdoba, Ferreyra Editor, 2013.

Amodio, Emanuele, «Curanderos y médicos ilustrados. La creación del Protomedicato en Venezuela a finales del siglo XVIII», Asclepio. Revista de Historia de la Medicina y de la Ciencia, 49:1, Madrid, 1997, 95-129.

Arcondo, Aníbal, La población de Córdoba en 1813, Córdoba, Universidad Nacional de Córdoba, Facultad de Ciencias Económicas, Instituto de Economía y Finanzas, 1995.

Aspell, Marcela, El tribunal de la Inquisición en América: los comisarios del Santo Oficio en Córdoba del Tucumán en el siglo XVIII, en Martiré, Eduardo (coord.), La América de Carlos IV. Cuadernos de investigaciones y documentos, II, Buenos Aires, Instituto de Investigaciones de Historia del Derecho, 2007.

Boixadós, Roxana y Faberman, Judith, «Clasificaciones mestizas. Una aproximación a la diversidad étnica y social en los Llanos riojanos del siglo XVIII», en Faberman, Judith y Ratto, Silvia (comps.), Historias mestizas en el Tucumán colonial y las pampas (siglos XVII-XIX), Buenos Aires, Biblos, 2009, 79-114.

Bubello, Juan Pablo, Historia del esoterismo en la Argentina: Prácticas, representaciones y persecuciones de curanderos, espiritistas, astrólogos y otros esoteristas, Buenos Aires, Biblos, 2010. 
Carbonari, María Rosa y Baggini, Iván, «Población y familias en la región del Río Cuarto. Fines del siglo XVIII», Quarto río, 7, Córdoba, 2004, 42-71.

Carbonari, María Rosa, Censo de 1778. Partido de Río Cuarto, Río Cuarto, Universidad Nacional de Río Cuarto, 2003.

Ceballos Gómez, Diana, «Grupos sociales y prácticas mágicas en el nuevo reino de Granada durante el siglo XVII», Historia Crítica, 22, Bogotá, 2001, 51-71.

Cebrelli, Alejandra, El discurso y la práctica de la hechicería en el NOA. Transformaciones entre dos siglos. Contribución al problema de la heterogeneidad sociocultural, Córdoba, Alción, 2008.

Celton, Dora, La población de la provincia de Córdoba a fines del siglo XVIII, Buenos Aires, Academia Nacional de la Historia, 1993.

Dainotto, Edgardo, Política y poder en Córdoba borbónica. Instituciones, espacios y prácticas (1783-1797), Córdoba, Ferreyra Editor, 2012.

Dominino Crespo, Darío, Escándalos y delitos de la gente plebe. Córdoba a fines del siglo XVIII, Córdoba, Editorial de la Facultad de Filosofía y Humanidades/Universidad Nacional de Córdoba, 2007.

Endrek, Emiliano, El mestizaje en Córdoba. Siglo XVIII y principios del XIX, Córdoba, Universidad Nacional de Córdoba, Instituto de Estudios Americanistas, 1966.

Farberman, Judith, Las salamancas de Lorenza. Magia, hechicería y curanderismo en el Tucumán colonial, Buenos Aires, Siglo XXI Editores Argentina, 2005.

Farberman, Judith y Ratto, Silvia, «Introducción», en Farberman, Judith y Ratto, Silvia (coords.), Historias mestizas en el Tucumán colonial y en las pampas. Siglos XVII al XIX, Buenos Aires, Biblos, 2009, 9-47.

Farberman, Judith, Magia, brujería y cultura popular: de la colonia al siglo XX, Buenos Aires, Sudamericana, 2010.

Farge, Arlette, La atracción del archivo, Valencia, Edicions Alfons El Magnánim, 1991.

Fernández, Sandra R. (comp.), Más allá del territorio. La historia regional y local como problema. Discusiones, balances y proyecciones, Rosario, Prohistoria, 2007.

Garcés, Carlos, «Místicos, curanderos y hechiceros: Historias de afroamericanos en la sociedad del Tucumán colonial», CONTRA|RELATOS desde el Sur, 7, Córdoba, 2010, 9-26.

Ginzburg, Carlo, El queso y los gusanos. El cosmos según un molinero del siglo XVI, Madrid, Ariel, 2016 [1. ${ }^{\mathrm{a}}$ ed. 1976].

Grana, Romina, «El expediente judicial, una construcción de sentidos», en González Navarro, Constanza (dir.), Prácticas de producción, ordenamiento y conservación del fondo de justicia colonial de Córdoba, Córdoba (Argentina), Centro de Estudios Históricos Profesor Carlos Segreti, 2017, 38-61.

Irigoyen López, Antonio, «Prólogo», en Ghirardi, Mónica y Siegrist, Nora (eds.), Amores Sacrílegos, Buenos Aires, Dunken, 2012, 7-11. 
Laviana Cuetos, María Luisa, «Brujería, curanderismo y religión en la provincia de Guayaquil a fines del siglo XVIII», Rábida, 6, Huelva, 1989, 58-70.

Laviana Cuetos, María Luisa, «Brujería, curanderismo y religión en la península de Santa Elena a fines del siglo XVIII», en Álvarez, Aurelio; Álvarez, Silvia G.; Fauría, Carmen y Marcos, Jorge G. (eds.), Primer Encuentro de Investigadores de la Costa Ecuatoriana en Europa. Arqueología, Etnohistoria, Antropología Sociocultural, Quito, Abya-Yala, 1995, 399-432.

Levaggi, Abelardo, Historia del Derecho Penal Argentino, Buenos Aires, Perrot, 1978.

Lockhart, James, «Organización y cambio social en la América española colonial», en Bethell, Leslie, (ed.), Historia de América Latina. Tomo 4: América Latina colonial: población, sociedad y cultura, Barcelona, Crítica, 2000, 63-108.

López Pereda, Marta, «Superstición, brujería y esclavitud en una sociedad colonial. Nueva España a mediados del siglo XVIII», tesis de maestría dirigida por Tomás A. Mantecón Movellán y Marina Torres Arce, Santander, Universidad de Cantabria, Facultad de Filosofía y Letras, 2014. Disponible en: https:// repositorio.unican.es/xmlui/bitstream/handle/10902/5501/LopezPeredaMar ta.pdf?sequence=1\&isAllowed=y [Consultado: 15/10/2020].

Nogueira, André Luís Lima, «Entre cirurgiões, tambores e ervas: calunduzeiros e curadores ilegais em ação nas Minas Gerais (século XVIII)», tesis doctoral dirigida por Lorelai Brilhante Kury, Río de Janeiro, Fundação Oswaldo Cruz, Casa de Oswaldo Cruz, Programa de Pós-Graduação em História das Ciências e da Saúde, 2013. Disponible en: https://www.arca.fiocruz.br/handle/ icict/16072 [Consultado: 15/10/2020].

Macagno, Mauricio Ernesto, «Salus populi, suprema lex: control de la medicina y el arte de curar en Argentina y el monopolio de la corporación médica. Un ensayo acerca de los antecedentes y motivos del delito de Ejercicio Ilegal de la Medicina, art. 208, Cód. Penal», Revista pensamiento penal, 22, Buenos Aires, 2011. Disponible en: http://www.pensamientopenal.com.ar/ doctrina/32616-salus-populi-suprema-lex-control-medicina-y-arte-curar-ar gentina-y-monopolio [Consultado: 15/10/2020].

Márquez Valderrama, Jorge; García, Víctor y Montoya, Piedad del Valle, «La profesión médica y el charlatanismo en Colombia en el cambio del siglo XIX al XX», Quipu, 14:3, Ciudad de México, 2012, 331-362.

Mayo, Carlos, «En torno al valor de la fuente judicial», en La fuente judicial en la construcción de la memoria, Mar del Plata, Universidad Nacional de Mar del Plata/Suprema Corte de Justicia de la Provincia de Buenos Aires, 1999, 583-586.

Moreyra, Cecilia, «Huellas de la población afromestiza en los archivos del Crimen. Córdoba del Tucumán a fines del siglo XVIII», en Celton, Dora y Colantonio, Sonia (coords.), Poblaciones vulnerables a través del tiempo: negros, mestizos, mendigos en Córdoba, siglos XVIII-XX, 2020, 15-46. 
Montes, Aníbal, Historia antigua de la ciudad de Río Cuarto, Córdoba, Universidad Nacional de Córdoba, 1953.

Olmedo, Ernesto y Tamagnini, Marcela, «La frontera sur de Córdoba a fines de la Colonia (1780-1809). Guerra, saber geográfico y ordenamiento territorial», Fronteras de la Historia, 24:1, Bogotá, 2019, 36-72.

Pizzo, Elizabeth Liliana, Mujeres y poder informal: salud, enfermedad y hechicería en la Córdoba del siglo XVIII, Córdoba, Universitas, 2004.

Presta, Ana María, «La sociedad colonial: raza, etnicidad, clase y género. Siglos XVI y XVII», Nueva Historia Argentina. Tomo II: La sociedad colonial, Buenos Aires, Sudamericana, 2000, 55-85.

Punta, Ana, Córdoba borbónica. Persistencias coloniales en tiempo de reformas (1750-1800), Córdoba, Universidad Nacional de Córdoba, 1997.

Punta, Ana, «La aplicación de la justicia en Córdoba a finales del siglo XVIII. Homicidios: pena de muerte y otros castigos», en VII Jornadas Interescuelas/ Departamentos de Historia, CD-Rom, Neuquén, Universidad Nacional del Comahue, 1999.

Punta, Ana, «La aplicación de la justicia en Córdoba a finales del siglo XVIII. Cambios y permanencias durante el gobierno del Marqués de Sobremonte», en Campos Álvarez, José Ramón y Rey Tristán, Eduardo (coords.), Actas del III Congreso Historiadores Latinoamericanistas, CD-Rom, Vigo, Universidad de Vigo/Universidad de Santiago de Compostela, 2002.

Quezada, Noemí, Enfermedad y maleficio. El curandero en el México colonial, Ciudad de México, Universidad Nacional Autónoma de México, Instituto de Investigaciones Antropológicas, 1989.

Rebagliati, Lucas, «La cárcel del cabildo de Buenos Aires y sus fuentes: aproximaciones, problemas y potencialidades (1776-1821)», Revista de Historia de las Prisiones, 6, Tucumán, 2018, 97-123.

Revel, Jacques, Juego de Escalas: experiencias de microanálisis, San Martín, Universidad Nacional de San Martín, 2015.

Rosso, Cintia, «Los hechiceros Guaycurúes en el Gran Chaco durante el Siglo XVIII», Maguaré, 26:1, Bogotá, 2012, 161-194.

Rufer, Mario, «Violencia, resistencia y regulación social de las prácticas: una aproximación a la esclavitud desde el expediente judicial. Córdoba, fines del siglo XVIII», Cuadernos de Historia. Serie Economía y Sociedad, 4, Córdoba, 2001, 195-230.

Rufer, Mario, Historias negadas: esclavitud, violencia y relaciones de poder en Córdoba a fines del siglo XVIII, Córdoba, Ferreyra Editor, 2005.

Rustan, María E., De perjudiciales a pobladores de la frontera. Poblamiento de la frontera sur de la Gobernación Intendencia de Tucumán a finales del siglo XVIII, Córdoba, Ferreyra Editor, 2005.

Souza, Rafael de Freitas, «Medicina e fauna silvestre em Minas Gerais no século XVIII», Varia Historia, 24:39, Minas Gerais, 2008, 273-291. 


\section{MARÍA DOLORES RIVERO Y CECILIA MOREYRA}

Vassallo, Jacqueline, Mujeres delincuentes. Una mirada de género en la Córdoba del siglo XVIII, Córdoba, Centro de Estudios Avanzados, Universidad Nacional de Córdoba, 2006.

Vassallo, Jaqueline, «La persecución de las prácticas mágicas en la Córdoba colonial (siglo XVIII)», Bulletin of Spanish Studies, 92:5, Londres, 2015, 831-853. 